\title{
Clinical profile of patients with Idiopathic Dilated Cardiomyopathy in a Tertiary Care Hospital of Bangladesh
}

\author{
Shabnam Jahan Hoque ${ }^{1^{*}}$, Aparna Rahman², Md. Zahid Alam, S M Rezaul Irfan ${ }^{1}$
}

\begin{abstract}
:
Background: High prevalence of Chronic heart failure due to Idiopathic Dilated Cardiomyopathy (DCM) is an important cause of heart failure in Bangladesh. This study was carried out to find the clinical characteristics of the patients with Idiopathic DCM, so that the data can be used to treat symptoms and improve survival and treatment.

Methodology: This prospective observational study was carried out in the Department of Cardiology, BIRDEM General Hospital, Dhaka, Bangladesh from January 2012 to December 2018. Total 50 consecutive admitted patients fulfilling the criteria of Idiopathic DCM were studied. Clinical information, findings from Echocardiography and other relevant investigations were collected for analysis.

Results: Among total 50 patients, 30(60.0\%) were male and 20(40.0\%) were female. Majority 20(40.0\%) patients belonged to age 51-60 years and their mean age was found 55.34 13.24 years. Using NYHA (New York Heart Association) functional status classification of the patients, 18(36.0\%) patients were found in NYHA class I, 15(30.0\%) in class II, 12(24.0\%) in class III and 5(10.0\%) in class IV. Almost all patients presented with three basic symptoms i.e. exertional dyspnea, easy fatigability and pedal edema. Orthopnea, Paroxosmal Nocturnal Dyspnoea (PND), palpitation \& chest pain wewe also reported in almost half of the patients. Mean pulse was found $88.78 \pm 15.75 \mathrm{beat} / \mathrm{min}$, respiratory rate $20.79 \pm 6.48 \mathrm{breath} / \mathrm{min}$, BMI $23.12 \pm 3.29 \mathrm{~kg} / \mathrm{m}^{2}$, systolic BP $119.03 \pm 22.22$ $\mathrm{mmHg}$ and diastolic BP $75.00 \pm 12.54 \mathrm{mmHg}$. Bilateral basal crepitation 45(90.0\%), Pedal edema 43(86.0\%), Raised JVP 39(78.0\%), Hepatomegaly 35(70.0\%) were also found. Third heart sound in 34(68.0\%), Pan systolic murmur of Mitral regurgitation 40(80.0\%), Pansystolic murmur of Tricuspid regurgitation was present in 42(84.0\%) among study patients. Mean left ventricular ejection fraction was found $30.44 \pm 4.91 \%$, LVIDs 5.24 $\pm 0.51 \mathrm{~cm}$ and LVIDd $6.18 \pm 0.52 \mathrm{~cm}$.
\end{abstract}

Conclusion: Majority of the Idiopathic DCM patients belonged to age 51-60 year age group with male predominance and clinical presentation was variable.

Key words: Dilated Cardiomyopathy (DCM), NYHA classification.

\section{Introduction:}

Cardiomyopathies are defined as "a heterogeneous group of diseases of the myocardium associated with mechanical and/or electrical dysfunction that usually (but not invariably) exhibit inappropriate ventricular hypertrophy or dilatation and are due to a variety of causes that frequently are genetic ${ }^{1}$. DCM refers to a group of heterogeneous myocardial disorders that are characterized by ventricle dilation and depressed myocardial contractility in the absence of abnormal loading conditions (such as hypertension or valvular disease) or ischemic heart disease sufficient to cause global systolic

\footnotetext{
1. Assistant Prof., Department of Cardiology, BIRDEM Genera Hospital,Dhaka

2. Assistant Prof., Department of Cardiology, Uttara Women's Medical College \&Hospital, Dhaka.

3. Associate Prof., Department of Cardiology, BIRDEM General Hospital,
}

\footnotetext{
*Corresponding Author:

Dr. Shabnam Jahan Hoque, FCPS (Medicine), D-card,

Assistant Prof., Department of Cardiology, BIRDEM General Hospital, Dhaka

Email: sjahanhoque@yahoo.com
}

impairment ${ }^{2,3}$. DCM is a primary myocardial disease of unknown cause characterized by left ventricular or biventricular dilatation and impaired myocardial contractility ${ }^{4}$ Idiopathic DCM is much more common than the other major forms of cardiomyopathy (hypertrophic, restrictive and arrhythmogenic right ventricular cardiomyopathy). It is a heterogeneous disease characterized by ventricular and sometimes atrial dilatation, with normal or reduced wall thickness, eventually leading to varying degrees of impaired systolic function. The clinical picture at the time of diagnosis can vary widely from patient to patient; some have no symptoms, whereas others have progressive refractory heart failure. Depending on the diagnostic criteria used, the reported annual incidence varies between 5 and 8 cases per 100,000 population $^{5-8}$. Males have a 2.5 fold increase in risk, as compared with females, that is unexplained by socioeconomic factors, alcohol intake or other variables ${ }^{5}$. Patients with idiopathic DCM can present a highly variable clinical course. The challenge is to identify and treat the known and treatable causes of idiopathic DCM early enough to improve symptoms and survival. The present study was aimed to study clinical characteristics of the patients admitted with idiopathic DCM in our perspective. 


\section{Materials and Methods:}

This prospective observational study was carried out in the Department of Cardiology, BIRDEM General Hospital, from January 2012 to December 2018. Total 50 consecutive patients admitted in BIRDEM fulfilling the criteria of idiopathic DCM were studied. Idiopathic DCM was diagnosed by the presence of left ventricular dilatation and systolic dysfunction on echocardiography in the absence of coronary artery disease, hypertension or valvular disease. In our study LV ejection fraction $<45 \%$ were labeled and included as DCM ${ }^{9}$. History taking, clinical examinations and Echocardiography in each case was done by two qualified cardiologist and if both agreed to label it as idiopathic DCM then cases were included in this study. The patients who were unwilling to participate, with coronary artery disease, cancer, concomitant infection at time of study, pregnancy, peripheral vascular disease, presence of other serious co-morbid medical or surgical illness or autoimmune disease, rheumatic heart disease, hypertrophic cardiomyopathy, hypertensive heart disease, and congenital heart disease, evidence of restrictive or constrictive physiology or alcohol intake $>60 \mathrm{~g} /$ day were excluded from study. Data were collected using structured questionnaire. The study was conducted following approval from Institutional Ethics Committee. After written informed consent, a detailed history was taken and thorough physical examination was carried out. Blood investigations in the form of complete blood count, liver function tests, renal function tests and lipid profile were done in all cases. Echocardiography of all the patients was done and ejection fraction was calculated using Simpson's method. Patients with ejection fraction less than $45 \%$ were labeled as DCM and enrolled in the study.

\section{Statistical Analysis:}

Data were presented as frequency, percentages, range or mean \pm standard deviation. Mean difference in continuous variables was analyzed using student T-test. For paired data, paired T-test was used. P values less than 0.05 was considered as significant. Results were analyzed using SPSS trial version 21.

\section{Results:}

Table I and II show the age and sex distribution respectively of the study population.

Table I

\begin{tabular}{lcc}
\hline Age (years) & $\begin{array}{c}\text { Number of patients } \\
\mathbf{N}=\mathbf{5 0}\end{array}$ & Percentage (\%) \\
\hline$\leq 40$ & 5 & 10.0 \\
$41-50$ & 13 & 26.0 \\
$51-60$ & 20 & 40.0 \\
$61-70$ & 7 & 14.0 \\
$>70$ & 5 & 10.0 \\
Mean \pm SD & & $55.34 \pm 13.24$ \\
\hline
\end{tabular}

Table II $(\mathrm{n}=50)$

\begin{tabular}{lcc}
\hline Sex & Number of patients & Percentage (\%) \\
\hline Male & 30 & 60.0 \\
Female & 20 & 40.0 \\
\hline
\end{tabular}

Table III shows NYHA functional classification status of the study patients $(\mathrm{N}=50)$

Table III

\begin{tabular}{lcc}
\hline $\begin{array}{l}\text { NYHA functional } \\
\text { status }\end{array}$ & $\begin{array}{c}\text { Number of } \\
\text { patients }\end{array}$ & Percentage (\%) \\
\hline I & 18 & 36.0 \\
II & 15 & 30.0 \\
III & 12 & 24.0 \\
IV & 5 & 10.0 \\
\hline
\end{tabular}

Table IV shows presenting symptoms profile of the patients (n $=50$ )

Table IV

\begin{tabular}{lcc}
\hline $\begin{array}{l}\text { Presenting } \\
\text { complaints }\end{array}$ & $\begin{array}{c}\text { Number of } \\
\text { patients }\end{array}$ & Percentage (\%) \\
\hline Dyspnoea & 45 & 90.0 \\
Fatigability & 43 & 86.0 \\
Pedal oedema & 39 & 78.0 \\
PND & 35 & 70.0 \\
Orthopnoea & 34 & 68.0 \\
Palpitation & 30 & 60.0 \\
Chest pain & 24 & 48.0 \\
Abdominal pain & 18 & 36.0 \\
Cough & 10 & 20.0 \\
Asymptomatic & 04 & 08.0
\end{tabular}

Table V shows Vital status of the patients $(n=50)$

Table V

\begin{tabular}{lcc}
\hline Vital status & Mean & $\pm \mathrm{SD}$ \\
\hline Pulse (beat/min) & 88.78 & \pm 15.75 \\
Respiratory rate (breath/min) 20.79 & \pm 6.48 \\
BMI $\left(\mathrm{kg} / \mathrm{m}^{2}\right)$ & 23.12 & \pm 3.29 \\
Systolic BP $(\mathrm{mmHg})$ & 119.03 & \pm 22.22 \\
Diastolic BP $(\mathrm{mmHg})$ & 75.00 & \pm 12.54 \\
\hline
\end{tabular}

Table VI shows Cardiac findings of the patients $(n=50)$ 
Table VI

\begin{tabular}{lcc}
\hline $\begin{array}{l}\text { Cardiac } \\
\text { findings }\end{array}$ & $\begin{array}{c}\text { Number of Percentage (\%) } \\
\text { patients }\end{array}$ \\
\hline Bilateral basal crepitation & 45 & 90.0 \\
Pedal oedema & 43 & 86.0 \\
Raised JVP & 39 & 78.0 \\
Hepatomegaly & 35 & 70.0 \\
Precordial finding & & \\
Third heart sound & 34 & 68.0 \\
Pansystolic murmur at apex (MR) & 40 & 80.0 \\
Pansystolic murmur at apex (TR) & 42 & 84.0 \\
SBP <100mmHg & 34 & 68.0 \\
\hline
\end{tabular}

Table VII shows gender based clinical characteristics $(n=50)$

Table VII

\begin{tabular}{lccc}
\hline & $\begin{array}{c}\text { Male }(\mathbf{n}=30) \\
\text { Mean } \pm \text { SD }\end{array}$ & $\begin{array}{c}\text { Female }(\mathbf{n}=20) \\
\text { Mean } \pm \text { SD }\end{array}$ & p value \\
\hline Age (years) & $53.2 \pm 10.0$ & $56.3 \pm 15.1$ & 0.535 \\
Pulse (beat/min) & $90.3 \pm 14.0$ & $87.8 \pm 17.1$ & 0.605 \\
$\begin{array}{l}\text { Respiratory } \\
\text { rate (breath/min) }\end{array}$ & $22.1 \pm 5.2$ & $19.9 \pm 7.1$ & 0.220 \\
$\begin{array}{l}\text { BMI }\left(\mathrm{kg} / \mathrm{m}^{2}\right) \\
\text { Systolic BP } \\
(\mathrm{mmHg})\end{array}$ & $22.4 \pm 3.5$ & $23.6 \pm 3.6$ & 0.467 \\
$\begin{array}{l}\text { Diastolic BP } \\
(\mathrm{mmHg})\end{array}$ & $78.6 \pm 12.5$ & $72.5 \pm 12.2$ & 0.098 \\
\hline
\end{tabular}

Table VIII shows Echocardiographic profile of idiopathic DCM cases $(n=50)$

\begin{tabular}{lc}
\hline Echocardiographic Parameter & Mean \pm SD \\
\hline LVEF (\%) & $30.44 \pm 4.91$ \\
LVIDs (cm) & $5.24 \pm 0.51$ \\
LVIDd (cm) & $6.18 \pm 0.52$ \\
RVIDd (cm) & $3.69 \pm 0.71$ \\
LAs (cm) & $4.20 \pm 0.59$ \\
\hline
\end{tabular}

LVEF: Left ventricular Ejection Fraction, LVIDs: Left ventricular internal diameter in systole; LVIDd: Left ventricular internal diameter in diastole, RVIDd: Right ventricular internal diameter in diastole, LAs: Left atrium in systole.

\section{Discussion:}

In our study, mean age of study subjects was $55.34 \pm 13.24$ years, $45(90 \%)$ were from $40-70$ years age group and majority $20(40.0 \%)$ patients belonged to age 51-60 years age group.
Age range was found to be $18-65$ years by Banerjee et al. ${ }^{10}$ and 18-80 years by Sonowal et al. ${ }^{11}$. The mean age of DCM patients was found 50.1 years by Flower et al. ${ }^{12}$ and it is almost similar to our study.

In our study $60.0 \%$ subjects were male and $40.0 \%$ were female. Male female ratio was 1.5:1 and this finding is close to other studies ${ }^{12-15}$. Sonowal et al. ${ }^{11}$ in their study found that $61.29 \%$ were male and $38.71 \%$ were female showing male female ratio to be 1.6:1. However, male-female ratio was reported to be higher (4:1) by Kuhn et al. ${ }^{13}$ and $2.33: 1$ by Banerjee et al. ${ }^{10}$

In this study $45(90.0 \%)$ patients had dyspnea, 43(86.0\%) fatigability, 39(78.0\%) swelling of legs, 35(70.0\%) PND, $34(68 \%)$ orthopnoea, $30(60 \%)$ palpitation, $24(48.0 \%)$ angina, $18(36.0 \%)$ abdominal pain, $10(20.0 \%)$ cough, and 4(8\%) was found asymptomatic. Sonowal et al. ${ }^{11}$ in their study on idiopathic DCM showed that most of the patients presented with dyspnea (70.97\%) followed by palpitation (64.52\%) and Fowler et al. ${ }^{12}$ found that dyspnea (89\%), dependent edema (89\%) were the most common presenting symptom, which are similar to our study. Banerjee et al. ${ }^{10}$ in their study observed that most common symptoms were dyspnea (86\%) and cough $(75 \%)$ though we got cough as presenting symptom in only $20 \%$ cases.

In our study it was observed that mean pulse was found $88.78 \pm 15.75$ beat $/ \mathrm{min}$, respiratory rate was $20.79 \pm 6.48$ breath/min, BMI was $23.12 \pm 3.29 \mathrm{~kg} / \mathrm{m}^{2}$, systolic BP was $119.03 \pm 22.22 \mathrm{mmHg}$ and diastolic BP was $75.00 \pm 12.54$ $\mathrm{mmHg}$. These observations were almost similar to Kumar et al. ${ }^{16}$ as they found the mean BMI was $21.36 \pm 1.46 \mathrm{~kg} / \mathrm{m}^{2}$, mean systolic BP was $125.7 \pm 8.27 \mathrm{mmHg}$ and mean diastolic BP was $75.83 \pm 4.19 \mathrm{mmHg}$.

In our study it was observed that majority of patients had bilateral basal crepitation $45(90.0 \%)$, others had pedal oedema 43(86.0\%), raised JVP 39(78.0\%) and hepatomegaly $35(70.0 \%)$. On precordial examination, third heart sound was present in $34(68.0 \%)$, Pansystolic murmur of Mitral Regurgitation 40(80.0\%), Pansystolic murmur of Tricuspid Regurgitation 42(84.0\%) and SBP $<100 \mathrm{mmHg} 34(68.0 \%)$. These clinical findings e.g. basal crepitation, pedal edema, hepatomegaly and third heart sound were comparable to study of Ahmed at al. ${ }^{16}$.

In our study mean LVEF was found $30.44 \pm 4.91 \%$, LVIDs $5.24 \pm 0.51 \mathrm{~cm}$ and LVIDd $6.18 \pm 0.52 \mathrm{~cm}$ which are almost similar to study of Goldberger et al. ${ }^{17}$ who found LVEF $30.6 \pm$ $11.4 \%$ and Saha et al. ${ }^{9}$ found LVEF $<40 \%$ in $73.4 \%$ cases, LVIDs $>5 \mathrm{~cm}$ in most of the cases and LVIDd $>6$ in $53.3 \%$ cases.

Our study found that there was no gender-based significant difference in age, pulse rate, respiratory rate, systolic and diastolic blood pressure. Similar observations were made by Kumar et al. ${ }^{18}$ and Narmani et al ${ }^{19}$.

Conclusion: Idiopathic Dilated cardiomyopathy was observed in middle aged and elderly population most commonly at 40-50 year age group with male predominance. 
The common presenting symptoms included exertional dyspnea, easy fatigability and pedal edema. Bilateral basal crepitation, Pedal edema, Raised JVP and Hepatomegaly were the common systemic findings. Gender-based difference was not significant in age, pulse rate, respiratory rate, systolic and diastolic blood pressure and the clinical presentations varied from patient to patient.

Limitation: The study was small and single centered. Therefore, a large population based multicenter prospective study is needed to understand the true picture and magnitude of the disease in Bangladesh.

\section{References:}

1. Maron BJ, Towbin JA, Thiene G, Antzelevitch C, Corrado D, Arnett D, Moss AJ. et al. Contemporary Definitions and Classification of the Cardiomyopathies. Circulation 2006; 113:1807-16

2. Richardson P, McKenna W, Bristow M, Maisch B, Mautner B, O'Connell J. Report of the 1995 World Health Organization/International Society and Federation of Cardiology Task Force on the Definition and Classification of cardiomyopathies. Circulation. Circulation. 1996;93(5):841-45

3. Kaur H, Khetarpal R, Aggarwal S. Dilated cardiomyopathy: an anaesthetic challenge. J Clin Diagn Res. 2013;7(6):1174-76.

4. Report of the WHO/ISFC task force on the definition and classification of cardiomyopathies. Br Heart J. 1980; 44:672- 73

5. Gillum RF. Idiopathic cardiomyopathy in the United States. Am Heart J. 1986; 111:752-55

6. Bagger JP, Baandrup U, Rasmussen K, Moller M, Vesterlund T. Cardiomyopathy in western Denmark. Br Heart J. 1984; 52:327-31

7. Williams DG, Olsen EGJ. Prevalence of overt dilated cardiomyopathy in two regions of England. Br Heart J 1985; $54: 153-55$

8. Codd MB, Sugrue DD, Gersh BJ, Melton LJ III. Epidemiology of idiopathic dilated and hypertrophic cardiomyopathy: a population-based study in Olmsted County, Minnesota. Circulation $1989 ; 80: 564-72$
9. Saha K, Kumar A, Sneha K, Kumar P, Mishra A, Tiwari M. et al.: A Clinical Study of Dilated Cardiomyopathy with Correlation to Electrocardiography and Echocardiography: A Cross Sectional Study. International Journal of Scientific Study 2018; 5:91-95

10. Banerjee SK, Rahman F, Salman M, Siddique MA, Zaman SMM, Anam K, Rahman M, et al. Idiopathic Dilated Cardiomyopathy: Clinical Profile of 100 Patients. University Heart Journal 2010; 6: 9-12.

11. Sonowal N, Rao VD. Clinical Profile of Patients with Dilated Cardiomyopathy in a Tertiary Care Center in North East India. Journal of Evolution of Medical and Dental Sciences 2014; 3: 8378-86.

12. Fowler NO, Gueron M, Rowlands DT. Primary myocardial disease. Circulation 1961; 23:498-508.

13. Kuhn H, Breithardt G, Knieriem HJ, Köhler E, Losse B, Seipel L, et al. Prognosis and possible presymptomatic manifestations of congestive cardiomyopathy (COCM). Postgrad Med J. 1978; 54: $451-59$.

14. Amoah AG, Kallen C. Aetiology of heart failure as seen from a national cardiac referral centre in Africa. Cardiology, 2000; 93: $11-18$.

15. Hibbard JU, Lindheimer M, Lang RM. A modified definition for peripartum cardiomyopathy and prognosis based on echocardiography. Obstet Gynecol 1999; 94: 311-16.

16. Ahmad S, Rabbani M, Zaheer M, Shirazi N. Clinical ECG and Echocardiographic profile of patients with dilated cardiomyopathy. Indian J Cardiol 2005; 8:25-29.

17. Goldberger JJ, Subacius H, Patel T, Cunnane R, Kadish AH. Sudden cardiac death risk stratification in patients with nonischemic dilated cardiomyopathy. J Am Coll Cardiol. 2014; 63(18):1879-89.

18. Kumar M, Sharma Y, Bahl A. Comparative Analysis of Clinical Profile of Patients Admitted with Idiopathic Dilated Cardiomyopathy in a Tertiary Care Hospital. J Cardiovasc Disease Res., 2017; 8:38-41.

19. Narmani G, Dilip MR, Karappa R. Etiological study of dilated cardiomyopathy in a tertiary care hospital Journal of Pharmaceutical and Biomedical sciences. 2014; 04(10):910-13. 